\title{
The Research Assessment Exercise as Sin
}

Mike Higton

In the most recent Research Assessment Exercise, the Theology 'Unit of Assessment' in which my own work was returned scored a ' 5 ' rating, a significant advance on our previous ' $3 \mathrm{a}$ ' score. This apparently tells us that we submitted a high proportion of work that was not just 'excellent' but 'internationally excellent', and that the standard of our research has improved measurably and markedly since 1996 . Yet, from a theological point of view, this is a strange claim. According to the discipline being assessed - as I shall try to explain - assessments of 'excellence' ought to be made in ways that are fundamentally conversational, that are themselves constitutionally open to judgment and revision, and that take time - possibly a great deal of time. Any form of assessment that tries to judge theological research in ways removed from genuine conversation, in some absolute way, and in a short and inflexible time, consequently looks rather odd.

For many centuries, theologians have reflected upon the forms of accountability appropriate to their discipline. I am thinking in particular of that wing of theology which does not so much concern itself with the accurate investigation of ancient texts, nor with the detailed reporting of religious behaviour and experience around the world, but rather concerns itself with giving an account of human flourishing, of the good, the true, and the beautiful - of, in theological terms, salvation. My own particular discipline is Christian theology, and such theology believes that it cannot talk about human flourishing fully without talking about God; that it cannot talk about human flourishing fully without 
thinking about the broadest and deepest possible contexts for that flourishing. As such, my discipline is one that takes as its subject matter a reality that does not simply lie ready to hand as one amongst other objects in the world. Theologians do not deal with a reality which could have theological hypotheses tested against it in some straightforward and transparent way, a reality that could have theological diagrams measured against it. We are repeatedly forced to ask how, in such a state of affairs, it is possible for us to be responsible and accountable for what we say. How can theological reflection be disciplined, rigorous, and open to critical judgment? What is it that makes it possible for theology to be an academic discipline?

Faced with such questions, theologians have long denied any model of their discipline that would make it resemble the accumulating of correct claims, the amassing of information. Instead they have seen themselves as faced with several responsibilities, all of which are refractions of the basic responsibility to do justice to talk about God. Theologians have, for instance, seen themselves as responsible for finding conceptual articulations of human flourishing that will be faithful to the existing life of Christian communities - both in the sense of finding articulations which do not close down or constrict that life, but also in the sense of finding forms of articulation which will help open that life up to appropriate judgments from outside itself, and help other communities learn from that life. Regarding themselves as having to reckon with God means that, however often theology has been tempted simply to become the propaganda office of existing institutions, it repeatedly finds itself facing and having to respond to a far broader context. 
To put this differently, theologians have repeatedly seen themselves as responsible to the world in which they find themselves (a world which they have regarded as, most fundamentally, a gift from God); responsible for developing conceptual resources which will allow the fullest and most honest attention to that world's constraints and possibilities; responsible for developing resources which will allow them to pay attention to the constant possibility that something different will turn out to be the case. We find ourselves working within a particular tradition of practice and thought, a tradition which believes and seeks to demonstrate that certain foundational commitments foster rather than obstruct such paying of attention to the world, but we constantly seek to find ways of refining and deepening that tradition in ways which will make it more broadly sensitive to the resistances which the world exhibits to any too-easy reading.

The form which 'falsification' or 'disconfirmation' takes in this context is not normally the discovery of an obvious and identifiable error, but rather the discovery that certain forms of theological articulation tend to constrict or deny the life of Christian communities, and constrict or deny the possibilities for human flourishing in the world. Of course, there is no way of stating the conditions for falsification neutrally. There is no way of stating what counts as 'life', 'flourishing', 'constriction' or 'denial' which does not already draw on some particular account of human flourishing, some particular theological articulation. Like others, theologians have no Archimedean point to which they can retreat and from which they can calmly judge the success or failure of their endeavours. Therefore it is often said that the form of theological truth is, or at least should be, 'conversational': the only form of accountability open to us, given that we cannot measure ourselves against any neutral standard, is serious engagement with the 
voices of those who see differently. Christian theology has, at different times, drawn the net of those who should be taken seriously in the conversation more or less widely, but the basic affirmation has been constant: the reality of which we attempt to speak is simply not of the kind that could be the possession of just one voice. To the extent that we are drawn towards greater conformity to that reality, it will be together: through the interaction and mutual qualification of multiple voices.

Of course, Christian theology privileges certain voices within that conversation (after all, at the heart of the tradition of Christian theology is the practice of returning again and again to particular voices from the past which, it is believed, provide a constant challenge to think differently; and the distinctiveness of Christian theology is largely due to its constant recourse to several voices from the Near East in the first century A.D); nevertheless, theology is and has always been carried on in actual fact, whether theologians like it or not, within a much wider conversation which stretches far beyond Christian communities. But whether the conversation is broad or narrow, by saying that the form of Christian theology is properly 'conversational', theologians mean that theological claims must remain, above all, open to judgment: open to the possibility that something else might be the case. They have meant to affirm that theology is not primarily about the defence of a single true voice, but rather about the practitioners of different forms of life taking one another seriously, holding one another to account.

In this kind of context, the assessment of any new claim or articulation unavoidably takes time; in the long experience of Christian theology it has often shown itself to be a process that can take decades, even centuries. Any faster attempts at assessment can only be tentative, pre-emptive attempts to guess or predict what will 
happen in communities that follow a certain path. It may from time to time be the case that, because certain paths have been found before to be constricting, they can be recognised and judged more quickly - but such judgments themselves are always open to revision. A history written by the victors cannot be an infallible guide for the faithful judgment of discarded possibilities. Admittedly, sometimes the constriction of life offered by a particular development seems so blatant, so obvious, that instead of the tentative judgment appropriate to theology, a more prophetic voice seems called for - but Christian theology has been adamant that, in the end, even prophecy needs to be tested, even prophecy is open to judgment. (And that means, of course, that even a prophetic denunciation of the Research Assessment Exercise should be open to judgment.)

There are many ways in which the Research Assessment Exercise sounds odd to theological ears. The Exercise claims to be 'evidence-based'; yet its framers have not asked how few of the truly great field-shaping works of theological history would have been recognised by a jury of peers within five years of publication. The Exercise seeks to build a research endeavour that is invulnerable to the charge that money is being wasted, or that poor work is being supported; Christian theology has long known that the only form of life that is invulnerable is death. The Exercise encourages departments, and individuals moving from department to department, to think in terms of accumulating a body of achieved work which is definitively 'ours' or 'mine', a personal store of brownie points which we can bargain for advancement; Christian theology has long held that a focus on the accumulation of personal merit is the surest route not to salvation but to damnation. 
The central problem with the Exercise is, however, more fundamental. The deepest rationale for the Exercise is a particular managerial vision of 'accountability'. New forms of Research Assessment may well be proposed which accept their fallibility and gives the benefit of the doubt more often; new forms may be proposed which do less to pit department against department, scholar against scholar. These would be welcome ameliorations. Any form of Research Assessment Exercise which seeks to serve anything like the same ends as the current form, however, will still regard itself as ensuring that the government, on behalf of the tax-payer, gets 'value for money' by arranging research in a league-table of 'excellence' and providing differential funding accordingly. This is not so much accountability as accounting: it is necessary to be able to arrange departments on some numerical scale of excellence, however artificial or notional that scale might be, in order to demonstrate to financial stakeholders that investment somehow matches returns. The investment is directly measurable; so must the returns be. Any Research Assessment Exercise worthy of the name will be inherently committed to producing, at the end of some fixed accounting period, an account of research returns which is structured by concepts of 'more' and 'less'.

Attempts to question the Research Assessment Exercise, when they are not met by arguments about practical necessity, are met by the claim that academic research must be accountable to those who ultimately fund it; any attempt to attack it must therefore be prepared to take scholarly accountability seriously. Theology, as I have been describing it (and I have drawn on arguments and ideas commonplace in contemporary theology), takes its accountability very seriously. The discipline is deeply committed to the investigation and promotion of human flourishing; it tries to render itself accountable for 
the articulations it gives of, and the interventions it makes in, the processes by which individuals and groups pursue visions of human flourishing. The primary question to be put to any suggested mechanisms for promoting 'accountability' in this context is: Will this proposed mechanism for accountability actually further our real accountability? Yet I have argued that the proper theological version of accountability is not one that lends itself to regular, definitive accounting: it takes time, it can only be conversational, and it can seldom be definitive. So we must ask of any proposed mechanism for 'accountability': Will this mechanism foster the conversation, the taking of time, and the openness to revision that are the proper forms of theological accountability?

It is obvious that the Research Assessment Exercise fails this test catastrophically. The Exercise promotes a form of assessment that assumes that there must be an end to taking time, that there has to be a quantitative standard of excellence that is simply available to view, and that assessment is not itself fundamentally conversational. This is not, in theological terms, accountability. Sending off work for instant judgment, effectively anonymous, removed from the possibility of genuine conversation, with the distant reader holding the gun of 'departmental finance' against one's head, has absolutely nothing to do with the accountability proper to academic theology, except as a denial or parody of it. It does not and cannot measure whether we are doing what we are supposed to be doing. It does not and cannot measure whether we are doing it better or worse than our neighbours. It does not and cannot have any grasp on whether what we are doing is 'excellent'. It does not and cannot have any grasp on whether we are being properly accountable to the society whose theologians we are. 
Only if the assessments of an Exercise panel could become part of the ongoing academic conversation, only if they could be responded to and argued with, only if that ongoing conversation could be allowed to take as much time as was necessary (years, decades, perhaps even centuries), only if it could be carried out in such a way as continually to be made aware of its relationship to the flourishing or decline of living communities, only if it could be carried out in such a way that all sorts of unexpected voices could join in - only, in fact, if it looked less like an assessment, and more like academic life at its best, could it claim to embody any relevant form of accountability. And if it looked like that, would it yield any results of use to a committee tasked with allocating funds?

There is and can be no way to check theological excellence that will satisfy a managerial culture. The managers may well cry that they must distribute the money somehow; but even if that is true one cannot deduce from it that there must be some way of measuring 'quality' in the short term. That such a measurement is, in fact, an impossibility means that the managers must be sent away to think differently. What they have tried to do, what they propose to continue doing, is an impossibility. The change in figures from 1991 to 1996 to 2001 tells us precisely nothing about the quality and accountability of the research work being done in our Universities - certainly in our departments of Theology, but I suspect that the same is true of many other disciplines. Anybody who believes that these figures actually convey information about the quality of research being done has simply not understood the first thing about what 'quality' has to mean in this context. Mesmerised by columns of figures (which take a lot of money to produce and so must be worth something), desperate for something to wave in front of the 
accountants in order to justify the allocation of funds to obscure academics, the managers have been seduced by moonshine.

The managers (and that means all of us, to the extent that we have breathed in this management culture, and have it multiplying in our guts) must learn that there can be things which deserve the investment of time, effort, and resources, because they contribute to the common good, but which cannot be measured within any plausible accounting cycle, which cannot be arranged on a numerical scale of excellence, and which cannot by their very nature be shown to be cost-effective. Here at least, management culture reaches a limit.

No Research Assessment Exercise can possibly do the job for which it is designed, because the job is impossible. The Exercise does not ensure accountability, but rather subjects research to a set of constraints which distract it from its proper accountability. For a theologian, the Exercise appears as an obstacle to the flourishing of the discipline, and as an obstacle to the discipline's proper concern with human flourishing, with salvation. For a theologian, then, the Research Assessment Exercise is a $\sin$. 